\title{
Impacto dos restaurantes populares na saúde e no desenvolvimento social dos usuários: o caso de Toledo (PR)
}

\author{
Mirian Beatriz Schneider \\ Universidade Estadual do Oeste do Paraná - PR - Brasil \\ Francielle Fonseca da Costa \\ Universidade Estadual do Oeste do Paraná - PR - Brasil
}

\section{Resumo}

A administração pública dos Restaurantes Populares do município de Toledo/PR recebeu um reconhecimento positivo dado Ministério de Desenvolvimento Social em 2015. Atentando-se a isto, este trabalho investigou os efeitos dos serviços prestados por este programa, por meio de mensuração e análise das opiniões dos usuários sobre as variáveis que condizem à gestão dos restaurantes populares e os efeitos para a saúde alimentar e desenvolvimento social dos mesmos, causados por participarem deste programa. Utilizou-se a metodologia de questionários de escala de Likert para a mensuração das opiniões e Partial Least Squares - PLS para testar as hipóteses do Modelo de Equações Estruturais aqui proposto. Constatou-se que os serviços prestados pelos Restaurantes Populares desse município causaram nos seus usuários efeitos positivos de saúde e de desenvolvimento social. Além disso, identificou-se o perfil socioeconômico dos usuários, o que evidenciou que os Restaurantes Populares são muito importantes para a população que tem renda mais restrita, possibilitando o acesso facilitado e de baixo custo à alimentação saudável.

Palavras-Chave: Restaurantes populares. Partial Least Squares. Desenvolvimento Social.

\section{Impact of popular restaurants on health and social development of users: the case of Toledo (PR)}

\section{Abstract}

The public administration of the Popular Restaurants of the city of Toledo/PR/BR received a positive acknowledgment from the Ministry of Social Development in 2015. In this regard, this work investigated the effects of the services provided by this program, through measurement and analysis of opinions of the users on the variables that correspond to the management of the popular restaurants and the effects for their food health and social development, caused by participating in this program. We used the Likert scale questionnaire methodology for the measurement of opinions and Partial Least Squares (PLS) to test the hypothesis of the proposed Structural Equations Model. It was found that the services provided by the Popular Restaurants of this city caused in its users positive health and social development effects. In addition, the socioeconomic profile of the users was identified, which showed that the popular restaurants are very important for the population that has more restricted income, allowing easy and low-cost access to healthy food.

Keywords: Popular Restaurants. Partial Least Squares. Social Development. 


\section{Impacto de los restaurantes populares en la salud y en el desarrollo social de los usuarios: el caso de Toledo (PR)}

\section{Resumen}

La administración publica de los restaurantes populares de la ciudad de Toledo/PR/BR, recibió un reconocimiento positivo del Ministerio de Desarollo Social en 2015. Por causa de esto, este trabajo investigo los efectos de los servicios prestados por este programa, por médio de mensuración y análisis de las opiniones de los usuarios sobre las variables que condicionan a la gestion de los restaurantes populares y los efectos para la salúd alimentar y desarollo social de los mismos. Causados por participar en este programa. Se utilizó la metodologia de cuestionarios de escala de Likert para la medición de las opiniones y Partial Least Squares (PLS) para probar las hipótesis del Modelo de Ecuaciones Estructurales aquí propuesto. Se constato que los servicios prestados por los Restaurantes Populares de la ciudad afectan positivamente la salud y lo desarollo social. Además, se identificó el perfil socioeconómico de los usuarios, lo que evidenció que los Restaurantes Populares son muy importantes para la población que tiene ingresos más restringidos, posibilitanto el acceso facilitado y de bajo costo a la alimentación saudable.

Palabras-Clave: Restaurantes Populares. Partial Least Squares. Desarrollo Social.

\section{Introdução}

O objetivo deste trabalho é quantificar a satisfação dos usuários quanto ao serviço oferecidos pelos restaurantes populares em Toledo/PR, bem como a sua opinião quanto as possíveis mudanças na saúde alimentar e melhorias de desenvolvimento social. A escolha pela opinião dos usuários para obterem-se os dados necessários à avaliação das variáveis citadas, se justifica por serem estes o foco do programa, logo, a ótica dos usuários, de forma realista e democrática, é reveladora da eficácia de sua execução, além de permitir o melhor conhecimento do perfil desses usuários (FERRAZ, et al, 2013). A questão central do trabalho trata de levantar qual é o real efeito dos Restaurantes Populares na Saúde e no Desenvolvimento Social dos Usuários na cidade de Toledo - PR.

No município de Toledo/PR existem cinco unidades de Restaurantes Populares (serão 8 até o final de 2016, salientando que em todo o estado existiam apenas 14 unidades até 2015), mais a Cozinha Social, onde são produzidas as refeições. Todos esses estabelecimentos são gerenciados pela administração pública, integrando-se a outros programas e políticas sociais, que envolvem e interligam a agricultura familiar regional, a alimentação escolar e a educação alimentar dos envolvidos. A gestão do programa, no município de Toledo, é reconhecida com prêmios, tais como, o primeiro lugar da $7^{a}$ edição do Prêmio Fundação Banco do Brasil de Tecnologia Social, primeiro lugar no Prêmio Josué de Castro conquistado pela Cozinha Social, segundo lugar no Prêmio Impar de 2015, e em 2016, conquistou a qualidade de boa prática de segurança alimentar pela ONU/FAO (FUNDAÇÃO BANCO DO BRASIL, 2013; FAO, 2016).

A utilização de Políticas Sociais no Brasil demonstra resultados positivos já nos primeiros anos do Século XXI. Na medida em que os gastos com políticas sociais aumentaram, a pobreza e a extrema pobreza diminuíram, como fica claro nos Gráficos 1 e 2. No período de 2000 até 2012, todo ano houve um incremento no montante dos gastos com Políticas Sociais, foram acrescentados 34,83 bilhões de reais por ano, em média, sendo que no ano de 2009 ocorreu o maior acréscimo, 
totalizando o montante de 84 bilhões de reais. Em contrapartida, a proporção de pobres, acatando a linha de pobreza, segundo o decreto 7492 de 2011 que instituiu o Plano Brasil sem Miséria, caiu, em média, 1.928\% por ano, no período de 2004 a 2012, apesar de ocorrer um elevação de $0.1 \%$ no ano de 2013. Comparando o primeiro e o último ano da série, a queda do índice proporção de pobres representa mais de $60 \%$.

O expressivo aumento dos gastos públicos em comparação à grande diminuição da pobreza, nesse período marcado pela proteção social, no Brasil, demonstra que a política social é eficaz para inclusão social e desenvolvimento da classe mais pobre, porém, os resultados das políticas sociais no país foram ainda maiores, tomando como exemplo o programa Bolsa Família, identificaram que "cada real investido no programa gera um retorno de $\mathrm{R} \$ 1,78$ para a economia e um efeito multiplicador de R\$2,40 sobre o consumo final das famílias” (BRASIL, 2013).

\section{Gráfico 1 - Evolução dos gastos em Políticas Sociais nos orçamentos da União} (Bilhões de R\$ de 2012)

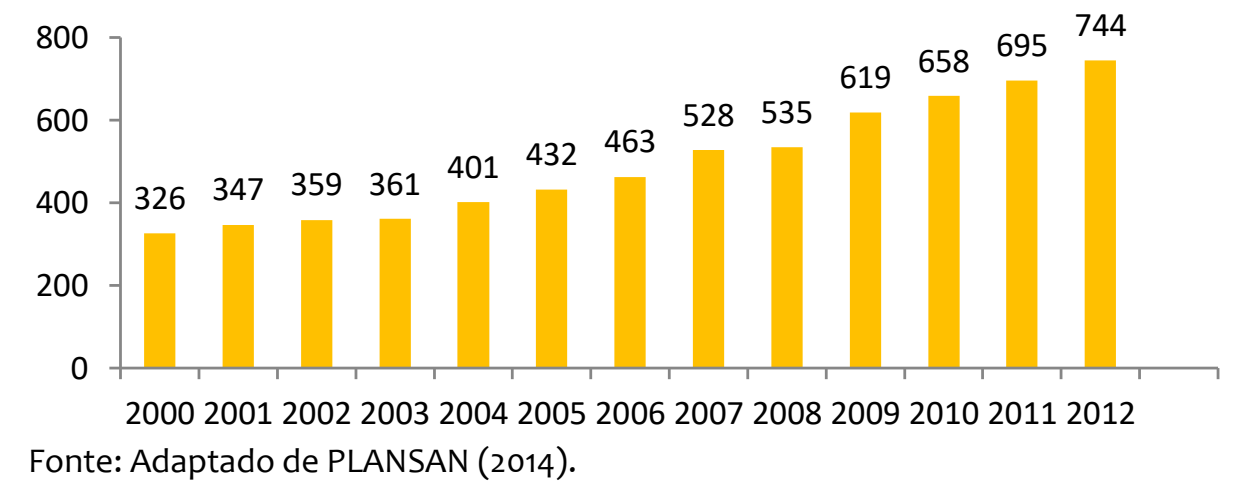

\section{Gráfico 2 - Proporção de pobres conforme linha de pobreza baseada no Decreto 7492 que instituiu o Plano Brasil Sem Miséria (\% do total da população)}

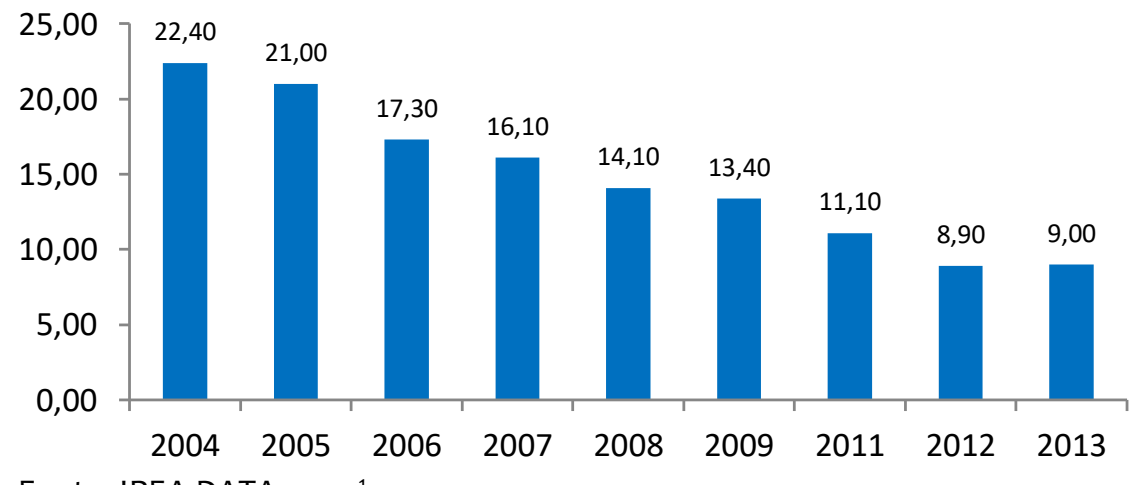

Fonte: IPEA DATA, $2015^{1}$.

Gráfico 3 - Desigualdade de Renda no Brasil - Índice de Theil

${ }^{1}$ O Decreto 7492 considera em extrema pobreza aquela população com renda familiar per capita mensal de até $\mathrm{R} \$ 70,00$ (setenta e sete reais), até Junho de 2011. Série calculada a partir dos dados da Pesquisa Nacional por Amostra de Domicílios (PNAD/IBGE). 


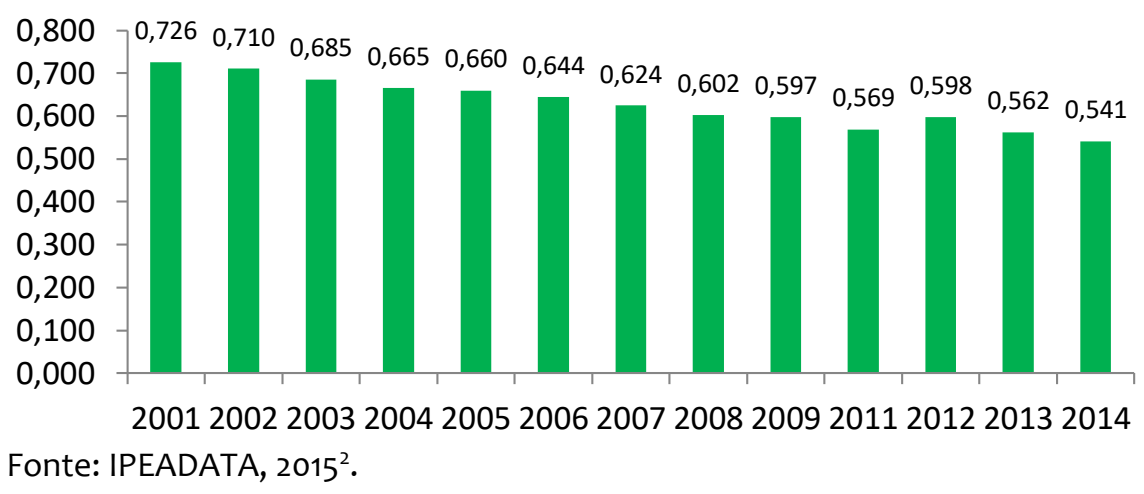

O índice de Theil é calculado por meio da equação $L=\ln \approx(\mu / \mu)$, ou seja, é o logaritmo da razão entre a média aritmética $(\mu)$ e a média geométrica $(\tilde{\mu})$ das rendas individuais da população de um país. Desse modo, se todas as rendas forem iguais, então $L=1$, indicando que quanto maior o índice de Theil, maior a desigualdade de renda. Dentre os anos de 2001 e 2014, observa-se que esse índice reduziu seu valor, não nas mesmas escalas como a proporção de pobres ou os gastos com políticas sociais, mas houve um pouco de melhora da desigualdade, pelo menos a de renda.

No período de 2003-2010, o Estado combateu as desigualdades, a pobreza e a fome, com uma série de programas, dentre eles o Fome Zero (2003), Bolsa Família (2004), o Programa de Erradicação do Trabalho Infantil (Peti) (2004); a Política de Segurança Alimentar e Nutricional, por meio do Sistema Nacional de Segurança Alimentar e Nutricional (Sisan) (2006), entre outros, de responsabilidade do Ministério de Desenvolvimento Social e Combate à Fome, com o foco na segurança alimentar pelo caráter emergencial no início dos anos 2000 (SILVA et al., 2010).

Com relação à segurança alimentar, pode-se observar no Gráfico 4 que, para os domicílios particulares, este índice melhorou, embora em pequena proporção ao longo do período de 2004 a 2013.

\footnotetext{
${ }^{2} \mathrm{O}$ Índice de Theil mede a desigualdade na distribuição de indivíduos segundo a renda domiciliar per capita. Série calculada a partir das respostas à Pesquisa Nacional por Amostra de Domicílios (Pnad/IBGE). É o logaritmo da razão entre as médias aritmética e geométrica das rendas individuais, sendo nulo quando não existir desigualdade de renda entre os indivíduos e tendente ao infinito quando a desigualdade tender ao máximo.
} 


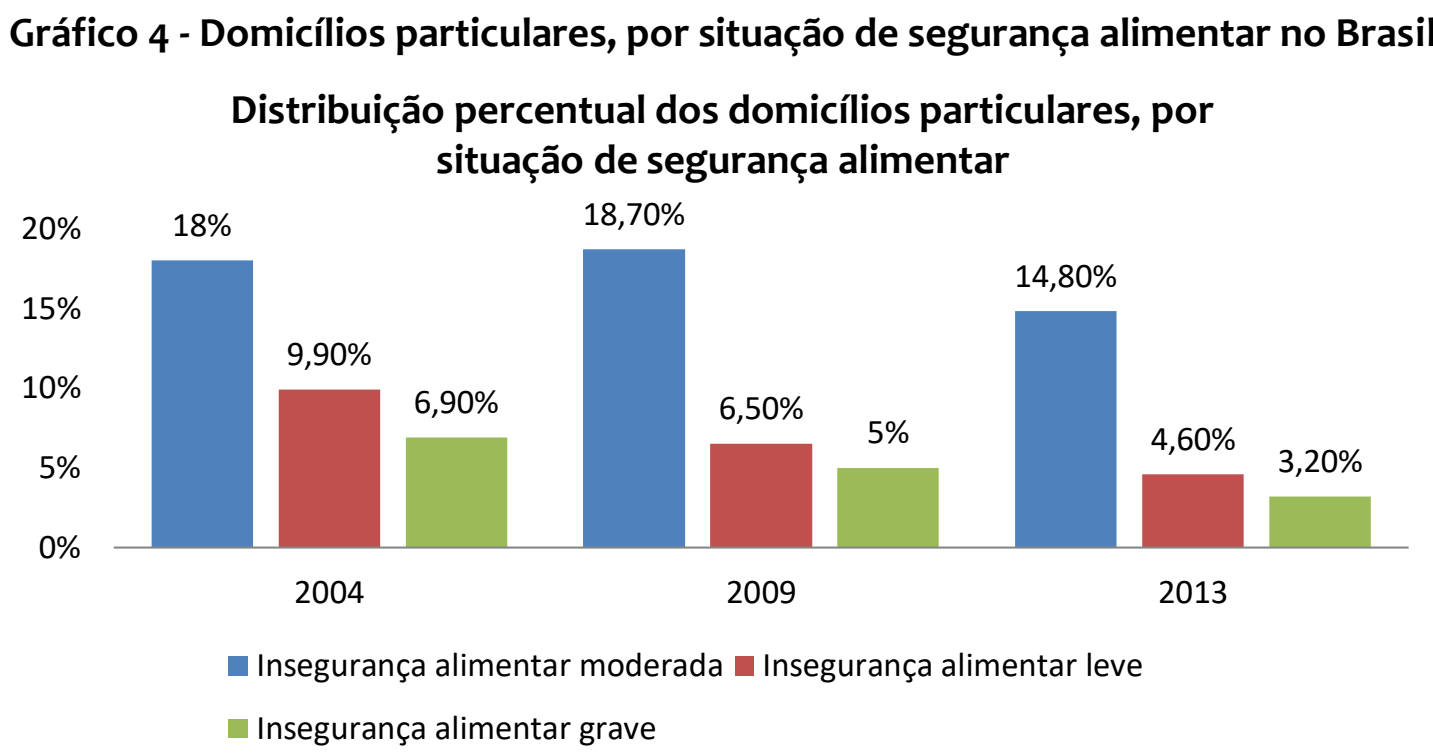

Fonte: IBGE, Diretoria de Pesquisas, Coordenação de Trabalho e Rendimento, Pesquisa Nacional por Amostra de Domicílios, 2013.

Em resposta a essas questões, o alimento é fornecido nos Programas de Combate à Fome, quando na forma material, não transferência de renda, visando atender a qualidade nutricional e impor a segurança alimentar aos usuários (CONSEA, 2009).

Atentando-se a ligação entre o problema da saúde alimentar com as desigualdades sociais e de renda, o Ministério de Desenvolvimento Social e Combate à Fome introduz nos objetivos dos seus programas o desenvolvimento social, na forma de bem-estar, inclusão social, economia de renda, e convivência dos usuários. Promover o fortalecimento da cidadania por meio da oferta de refeições em ambientes limpos, confortáveis e em conformidade com as orientações dos órgãos de vigilância sanitária, favorecendo a dignidade e a convivência entre os usuários [...], disponibilizar o espaço do Restaurante Popular para realização de atividades de interesse da sociedade (MDS, 2004, P. 6-7).

\section{Os Restaurantes Populares de Toledo/PR}

Os Restaurantes Populares são, segundo a apresentação do programa pelo MDS, uma ação do programa Fome Zero (2003) de combate à fome e exclusão social, que visa a ampliação da oferta de refeições saudáveis a preços acessíveis, contribuindo assim, para a redução do número de pessoas em situação de insegurança alimentar. O objetivo geral dos Restaurantes Populares é oferecer refeições saudáveis, nutricionalmente balanceadas, originadas de processos seguros e comercializada a preços acessíveis, em local confortável e de fácil acesso (MDS, 2007a).

Os objetivos específicos do programa buscam integrar a cidadania, a dignidade dos trabalhadores dos restaurantes e dos usuários, bem como prover espaços físicos limpos e aconchegantes para as refeições. O público-alvo são principalmente pessoas em situação de insegurança alimentar e vulnerabilidade social, de modo que as instalações físicas dos restaurantes devem se localizar nas 
cidades com mais de 100 mil habitantes especificamente em regiões com considerável circulação de pessoas de baixa renda, que possam se locomover até o local sem precisar de meio de locomoção (MDS, 2007a).

Os Restaurantes Populares são equipamentos de uma estrutura multifuncional, assim além da produção e distribuição de refeições, agrega atividades como desenvolvimento social, geração de emprego e renda. São necessárias instalações físicas adequadas para serem implantados e acolher os usuários e colaboradores:

\footnotetext{
1-Setores de Recepção, Pré-Higienização, Estocagem e Administração (recepção/pré-higienização + administração/controle + despensa seca + depósito de material de limpeza + depósito de caixas + câmaras frias + vestiários/sanitários de funcionários);

2-Setor da Cozinha (sala do profissional de nutrição + setor de cocção + setores de pré-preparo + setores de higienização de utensílios + depósito de lixo);

3-Setor do Refeitório (hall de entrada dos usuários + salão de mesas + sanitários de usuários) (MDS, 2007b, p. 8).
}

A responsabilidade de gestão dos restaurantes fica a cargo das unidades de administração pública, Governos Estaduais ou Governos Municipais, mas pode acontecer com a parceria de organizações sem fins lucrativos, que abrangem o âmbito da segurança alimentar, como por exemplo, Polícia Militar, Corpo de Bombeiros, CRAS, etc. Pode-se optar por terceirizar a operacionalização comercial e industrial dos restaurantes, porém ainda fica a cargo da administração pública os subsídios para preços acessíveis e a avaliação e monitoramento dos serviços (MDS, 2007a)

Para Vasconcelos (2005), no Brasil os Restaurantes Populares são uma experiência vitoriosa, sendo o programa um meio para solucionar o problema da subalimentação da população mais vulnerável. Em Toledo-PR existem seis unidades, um restaurante popular localizado no Bairro Coopagro inaugurado em 2006, um no Bairro Boa Esperança e outro no Bairro Jardim Europa inaugurados em 2007, um no Bairro São Francisco inaugurado em 2008, um restaurante no Bairro Vila Paulista inaugurado em 2011, e um no Jardim La Salle, inaugurado em 2016, que atendem às diretrizes dos objetivos propostos pelo MDS. Porém, primeiramente, em 2006, foi criada a Cozinha Social, que é a unidade de produção industrial das refeições que são oferecidas nos restaurantes e nas outras entidades municipais que foram incluídas no projeto posteriormente, (BRASIL, 2015).

A Administração Pública decidiu manter os Restaurantes Populares de Toledo no âmbito da gestão pública, sem recorrer a terceirização do restaurante em si. Foram distribuídas em média, em 2015, 1.920 refeições por dia, ao preço de $R \$ 2,50$, durante o horário de almoço entre 11:30 e 13:30 horas, com cardápios variados de teor nutritivo e saudável, e alimento de qualidade, sempre elaborados e acompanhados pela nutricionista responsável (PREFEITURA DE TOLEDO, 2014). O custo de cada refeição é de $R \$ 6,52$, sendo que a parte subsidiada pelo Governo Federal representa $\mathrm{R} \$ 1,50$ e pelo município de $\mathrm{R} \$ 2,50$ do valor total. O programa se estende, também, a outras políticas existentes na cidade de Toledo nas áreas da agricultura familiar, de segurança alimentar e de incentivos à produção de alimentos, como bem demonstra o Quadro 1. 


\section{Quadro 1 - Políticas Públicas que interagem com os Restaurantes Populares, Toledo/PR}

\begin{tabular}{|c|c|}
\hline POLÍTICAS PÚBLICAS & OBJETIVOS DAS POLÍTICAS \\
\hline $\begin{array}{l}\text { PROGRAMA DE } \\
\text { AQUISIÇÃO DE } \\
\text { ALIMENTOS (PAA) }\end{array}$ & $\begin{array}{c}\text { Política pública do Governo Federal criada em } 2003 \text { com o objetivo de } \\
\text { contribuir com o combate a fome e a pobreza no Brasil e, também, } \\
\text { fortalecer a agricultura familiar. }\end{array}$ \\
\hline COMPRA DIRETA & $\begin{array}{l}\text { Modalidade do PAA que possibilita a formação de estoques públicos, } \\
\text { destinados ao abastecimento social ou a venda, por meio da compra de } \\
\text { produtos específicos que são usados na composição de cestas para } \\
\text { distribuição. }\end{array}$ \\
\hline $\begin{array}{l}\text { APOIO À FORMAÇÃO DE } \\
\text { ESTOQUES PELA } \\
\text { AGRICULTURA FAMILIAR }\end{array}$ & $\begin{array}{l}\text { Modalidade do PAA que fornece apoio financeiro, para formação de } \\
\text { estoques de alimentos por organizações ou associações da agricultura } \\
\text { familiar, para posteriormente serem vendidos, proporciona aos } \\
\text { produtores familiares, meios de apoio à comercialização, segurança de } \\
\text { preços e agregar valor aos seus produtos. }\end{array}$ \\
\hline $\begin{array}{l}\text { INCENTIVO À PRODUÇÃO } \\
\text { E AO CONSUMO DE LEITE }\end{array}$ & $\begin{array}{l}\text { Modalidade do PAA que auxilia no aumento do consumo de leite pelas } \\
\text { famílias em situação de insegurança alimentar e nutricional e fortalece a } \\
\text { produção leiteira dos agricultores familiares. }\end{array}$ \\
\hline COMPRA INSTITUCIONAL & $\begin{array}{c}\text { Modalidade do PAA que permite que estados, municípios e órgãos } \\
\text { federais da administração direta e indireta façam a compra de produtos } \\
\text { dos produtores rurais pelas chamadas públicas, utilizando recursos } \\
\text { próprios e sem licitação. }\end{array}$ \\
\hline $\begin{array}{l}\text { COMPRA DE DOAÇÃO } \\
\text { SIMULTÂNEA }\end{array}$ & $\begin{array}{c}\text { Modalidade do PAA que atende estabelecimentos locais de } \\
\text { suplementação alimentar. Os produtos adquiridos dos agricultores } \\
\text { familiares são doados às entidades (Restaurantes Populares, Cozinhas } \\
\text { Comunitárias e Bancos de Alimentos). }\end{array}$ \\
\hline $\begin{array}{l}\text { PROGRAMA NACIONAL } \\
\text { DE FORTALECIMENTO DA } \\
\text { AGRICULTURA FAMILIAR } \\
\text { (PRONAF) }\end{array}$ & $\begin{array}{l}\text { Política pública do Governo Federal, criado em } 1995 \text { para apoiar } \\
\text { financeiramente as atividades agropecuárias ou não, para implantação, } \\
\text { ampliação ou modernização da estrutura de produção, beneficiamento, } \\
\text { industrialização e de serviços, no campo ou em áreas comunitárias rurais } \\
\text { próximas. É destinado para promover a expansão da produção e da } \\
\text { produtividade e também para a redução dos custos de produção. }\end{array}$ \\
\hline $\begin{array}{l}\text { MAIS ALIMENTOS } \\
\text { PRODUÇÃO PRIMÁRIA }\end{array}$ & $\begin{array}{c}\text { Modalidade do PRONAF é uma linha de crédito que financia investimentos } \\
\text { em infraestrutura produtiva da agricultura familiar }\end{array}$ \\
\hline $\begin{array}{l}\text { PROGRAMA DE } \\
\text { GARANTIA DE PREÇOS } \\
\text { PARA A AGRICULTURA } \\
\text { FAMILIAR }\end{array}$ & $\begin{array}{l}\text { Modalidade do PRONAF que garante aos produtores familiares, em caso } \\
\text { de baixa de preços dos alimentos no mercado, um desconto no valor do } \\
\text { financiamento, sendo esse desconto a diferença entre o preço de } \\
\text { mercado e o preço de garantia do produto. }\end{array}$ \\
\hline $\begin{array}{l}\text { ASSISTÊNCIA TÉCNICA E } \\
\text { EXTENSÃO RURAL }\end{array}$ & $\begin{array}{l}\text { Modalidade do PRONAF que fornece assistência técnica aos agricultores } \\
\text { desde o início da safra até o mercado. }\end{array}$ \\
\hline $\begin{array}{l}\text { PROGRAMA NACIONAL } \\
\text { DE SEGURANÇA } \\
\text { ALIMENTAR E } \\
\text { NUTRICIONAL (PNSAN) }\end{array}$ & $\begin{array}{l}\text { Política Política pública do Governo Federal que garante a segurança } \\
\text { alimentar e nutricional da população brasileira. }\end{array}$ \\
\hline $\begin{array}{l}\text { PROGRAMA NACIONAL } \\
\text { DE ALIMENTAÇÃO } \\
\text { ESCOLAR (PNAE) }\end{array}$ & $\begin{array}{l}\text { Política pública do Governo Federal que contribui para o crescimento, o } \\
\text { desenvolvimento, a aprendizagem, o rendimento escolar dos estudantes e } \\
\text { a formação de hábitos alimentares saudáveis, por meio da oferta da } \\
\text { alimentação escolar e de ações de educação alimentar e nutricionais. }\end{array}$ \\
\hline
\end{tabular}

Fonte: Adaptado de ZANINI, 2015, p. 40.

O cruzamento da política dos restaurantes populares com a política do PAA integrou duas áreas sociais, a dos usuários, e a dos produtores da agricultura familiar, 
focos da política social do Ministério de Desenvolvimento Social e Combate à Fome: desenvolvimento social, incentivo à agricultura familiar e acesso a alimentação de qualidade para os indivíduos mais vulneráveis da sociedade (MDA, 2015).

Essa integração teve efeitos positivos neste município tanto para os agricultores familiares quanto para os usuários dos Restaurantes Populares. Para os agricultores surge mais uma opção para direcionar sua produção no mercado, contribuindo para a geração de mais empregos no campo, e diminuição do êxodo rural e do índice de pobreza no campo. Para os usuários dos Restaurantes Populares, aumenta-se a variedade, a qualidade e o controle de estoque dos alimentos.

Além disso, essa junção de políticas promove a economia de matéria-prima e diminuição do desperdício com padronização das receitas e dos processos, o controle higiênico sanitário, e a possível mudança positiva de hábito alimentar dos usuários, considerando o aumento da oferta de verduras e legumes observado nos restaurantes (ZANINI, 2015; HENRIQUE, 2013).

Percebe-se a grande dimensão que o programa Restaurantes Populares alcançou nesta cidade, devido a iniciativa pública que promoveu os esforços necessários a implantação, organização, integração, e acessibilidade à política pública, através do reconhecimento pelo próprio MDS, prêmios de gestão e pelas visitas de outras cidades interessadas no modelo, incluem-se países vizinhos, a Argentina e o Paraguai (FUNDAÇÃO BANCO DO BRASIL, 2013; ZANINI, 2015). Isto também foi o incentivo para esta pesquisa, dada a importância do levantamento de dados e da avaliação e acompanhamento desta política pública social para este município.

\section{Procedimentos Metodológicos}

Os dados que foram trabalhados basearam-se em um questionário aplicado aos usuários, e foram analisados quantitativamente, através da metodologia de Partial Least Squares (PLS) e qualitativamente com metodologia descritiva.

Quadro 2 - Resumo dos procedimentos metodológicos

\begin{tabular}{|c|c|c|c|c|}
\hline $\begin{array}{c}\text { Classificação } \\
\text { quantos aos } \\
\text { objetivos da } \\
\text { pesquisa }\end{array}$ & $\begin{array}{c}\text { Classificação } \\
\text { quanto à natureza } \\
\text { da pesquisa }\end{array}$ & $\begin{array}{c}\text { Classificação } \\
\text { quanto à escolha } \\
\text { do objeto de } \\
\text { estudo }\end{array}$ & $\begin{array}{c}\text { Classificação } \\
\text { quanto à técnica } \\
\text { de coleta de dados }\end{array}$ & $\begin{array}{c}\text { Classificação } \\
\text { quanto à técnica } \\
\text { de análise de } \\
\text { dados }\end{array}$ \\
\hline $\begin{array}{l}\checkmark \text { Bibliográfica } \\
\checkmark \text { Exploratória } \\
\checkmark \text { Descritiva }\end{array}$ & $\checkmark$ Qualitativa & $\checkmark$ Estudo de caso & $\checkmark$ Questionário & $\checkmark$ Descritiva \\
\hline
\end{tabular}

Fonte: Dados da Pesquisa, 2015. 


\subsection{Questionário e amostra}

A base para elaboração dessa pesquisa foi retirada da opinião dos usuários sobre a gestão do programa em análise, para tanto, se fez necessário o uso de questionário.

Para a pesquisa de opinião, foi utilizada a escala de Likert de 7 pontos, onde as respostas para cada item variam segundo o grau de intensidade. Essa escala com categorias ordenadas, igualmente espaçadas e com mesmo número de categorias em todos os itens, é largamente utilizada em pesquisas organizacionais, e estatísticas (ALEXANDRE, et. al, 2003).

Dessa forma, os usuários puderam expressar sua opinião quanto aos itens questionados, respondendo entre 1 e 7 , sendo que 1 nada condiz com a teoria que embasa este estudo, ou seja, os serviços prestados pelos Restaurantes Populares não alcançaram em nenhum nível o seu objetivo e 7 condiz totalmente, o que significa que os serviços prestados pelos Restaurantes Populares alcançaram no melhor nível o seu objetivo. Como mostra o Quadro 3, cada resposta corresponde a uma observação de uma variável utilizada na metodologia, de acordo com o assunto da questão.

\section{Quadro 3 - Formação das variáveis utilizadas na Modelagem de Equações Estruturais}

\begin{tabular}{|c|c|c|}
\hline Questões no Questionário (ANEXO B) & Representação em Variáveis & Referências Bibliográficas \\
\hline $\begin{array}{l}\text { Serviços prestados pelo Restaurante } \\
\text { Popular }\end{array}$ & RESTAURANTE POPULAR (RPS) & RESTAURANTE POPULAR (RPS) \\
\hline $\begin{array}{l}\text { 1. Qual a sua opinião sobre o preço } \\
\text { cobrado no Restaurante Popular? (1. } \\
\text { nada barato e } 7 \text {. Muito barato) }\end{array}$ & Preço da Refeição (PR) & \multirow{6}{*}{ PREFEITURA DE TOLEDO, 2014.} \\
\hline $\begin{array}{l}\text { 2. Qual a sua opinião sobre a qualidade } \\
\text { do alimento oferecido? (1. nada saudável } \\
\text { e 7. Muito saudável) }\end{array}$ & Qualidade do Alimento (QA) & \\
\hline $\begin{array}{l}\text { 3. Qual a sua opinião sobre a higiene do } \\
\text { ambiente onde se serve? (1. Nada } \\
\text { higiênico e } 7 \text {. Muito higiênico) }\end{array}$ & Higiene Local (HL) & \\
\hline $\begin{array}{l}\text { 4. Qual a sua opinião sobre a localização } \\
\text { do Restaurante Popular? (1. Nada } \\
\text { acessível e 7. Muito acessível) }\end{array}$ & Localização dos RPs (LO) & \\
\hline $\begin{array}{l}\text { 5. Qual a sua opinião sobre os } \\
\text { equipamentos fornecidos pelo } \\
\text { Restaurante popular para se servir? } \\
\text { (Considere utensílios para se servir, } \\
\text { como garfos, copos, pratos, etc.) (1. } \\
\text { nada bons/nada úteis e } 7 \text {. Muito bons, } \\
\text { Muito úteis) }\end{array}$ & Equipamentos Públicos (EQ) & \\
\hline $\begin{array}{l}\text { 6. Qual a sua opinião sobre o } \\
\text { atendimento que você recebeu no } \\
\text { Restaurante Popular? (1. Nada bom e } 7 . \\
\text { Muito bom) }\end{array}$ & Atendimento nos RPs (AT) & \\
\hline
\end{tabular}


(conclusão)

\begin{tabular}{|c|c|c|}
\hline Questões no Questionário (ANEXO B) & Representação em Variáveis & Referências Bibliográficas \\
\hline Saúde Alimentar dos Usuários & SAÚDE DOS USUÁRIOS (SU) & SAÚDE DOS USUÁRIOS (SU) \\
\hline $\begin{array}{l}\text { 7. Qual o grau de aprendizagem que } \\
\text { você adquiriu sobre alimentação } \\
\text { saudável como prevenção de doenças } \\
\text { por frequentar o Restaurante Popular? } \\
\text { (1. Nada de aprendizado e 7. Muito } \\
\text { aprendizado) }\end{array}$ & $\begin{array}{c}\text { Aprendizagem sobre Segurança } \\
\text { Alimentar (AS) }\end{array}$ & \multirow{4}{*}{$\begin{array}{l}\text { CONSEA, } 2009 . \\
\text { MDS, } 2004 . \\
\text { MDS, 2007a. } \\
\text { MDS, 2007b. }\end{array}$} \\
\hline $\begin{array}{l}\text { 8. Qual o grau de mudança de hábito } \\
\text { alimentar que você adquiriu por } \\
\text { frequentar o restaurante Popular (Se } \\
\text { você leva para a sua vida a opção de } \\
\text { alimentação saudável, como diminuir o } \\
\text { consumo de carnes e gordura, e } \\
\text { aumentar o consumo de verduras e } \\
\text { legumes)? (1. Nada de mudança e } 7 \text {. } \\
\text { Muita mudança) }\end{array}$ & $\begin{array}{l}\text { Mudança de hábito alimentar } \\
\text { (MA) }\end{array}$ & \\
\hline $\begin{array}{l}\text { 9. Você costuma vir ao Restaurante } \\
\text { Popular caminhando? (1. Nunca e } 7 . \\
\text { Sempre) }\end{array}$ & Prática de caminhada (PC) & \\
\hline $\begin{array}{l}\text { 10. Com o tempo gasto para se alimentar } \\
\text { no Restaurante Popular ainda te sobra } \\
\text { tempo para descansar após a refeição, } \\
\text { ou para fazer outras atividades de seu } \\
\text { interesse? (1. Não sobra tempo e } 7 \text {. Sobra } \\
\text { bastante tempo) }\end{array}$ & $\begin{array}{c}\text { Tempo ganho para descanso } \\
\text { (TD) }\end{array}$ & \\
\hline Desenvolvimento Social dos Usuários & $\begin{array}{l}\text { DESENVOLVIMENTO SOCIAL } \\
\text { DOS USUÁRIOS (DS) }\end{array}$ & $\begin{array}{c}\text { DESENVOLVIMENTO SOCIAL DOS } \\
\text { USUÁRIOS (DS) }\end{array}$ \\
\hline $\begin{array}{l}\text { 11. A economia que você tem por se } \\
\text { alimentar no restaurante popular é } \\
\text { usada para consumo de outras coisas } \\
\text { que te propiciam bem-estar e cultura? (1. } \\
\text { Não uso para consumir nada de bem- } \\
\text { estar e cultura e } 7 . \text { Uso Bastante para } \\
\text { esta finalidade) }\end{array}$ & $\begin{array}{l}\text { Consumo invertido em bem- } \\
\text { estar e cultura (CBE) }\end{array}$ & \multirow{5}{*}{$\begin{array}{l}\text { MDS, } 2004 . \\
\text { MDS, } 2007 a .\end{array}$} \\
\hline $\begin{array}{l}\text { 12. A economia que você tem por se } \\
\text { alimentar no restaurante popular é } \\
\text { usada para consumo de outras coisas no } \\
\text { bairro do próprio restaurante? (1. Não } \\
\text { uso para consumir nada neste bairro e } 7 . \\
\text { Uso muito para consumir neste bairro) }\end{array}$ & $\begin{array}{l}\text { Consumo invertido na região } \\
\text { (CR) }\end{array}$ & \\
\hline $\begin{array}{l}\text { 13. Como você classifica a rapidez para } \\
\text { ser atendido, considerando tempo em } \\
\text { filas e para almoçar? (1. Nada rápido e } 7 \text {. } \\
\text { Muito rápido) }\end{array}$ & Tempo gasto em filas (TG) & \\
\hline $\begin{array}{l}\text { 14. Você interage com os outros usuários } \\
\text { que almoçam aqui no Restaurante } \\
\text { Popular (Se você cumprimenta, } \\
\text { conversa, faz amizades)? (1. Nunca e } 7 . \\
\text { Sempre) }\end{array}$ & Interação Social e Humana (IS) & \\
\hline $\begin{array}{l}\text { 15. Você participa de eventos, reuniões } \\
\text { da comunidade, ou apresentações } \\
\text { culturais que são feitas no espaço do } \\
\text { Restaurantes Populares? (1. Nunca e } 7 \text {. } \\
\text { Sempre) }\end{array}$ & $\begin{array}{l}\text { Ganhos de cultura e } \\
\text { socialização (CS) }\end{array}$ & \\
\hline
\end{tabular}

Fonte: Dados da pesquisa, 2015. 
Para se obter uma amostragem probabilística que capacita a admissão dos resultados desta para a população, utiliza-se o cálculo amostral expresso na seguinte fórmula:

$$
n=\frac{N \cdot Z^{2} \cdot p \cdot(1-p)}{Z^{2} \cdot p \cdot(1-p)+e^{2} \cdot(N-1)}
$$

Em que:

n - amostra calculada;

$\mathrm{N}$ - população;

Z - variável normal padronizada associada ao nível de confiança;

p - verdadeira probabilidade do evento;

e - erro amostral (SANTOS, 2015).

Quadro 4 - Média diária de refeições servidas nos Restaurantes Populares de Toledo/PR

\begin{tabular}{|c|c|}
\hline Unidade dos Restaurantes Populares & Média Diária de Refeições Servidas \\
\hline Jardim Coopagro & 510 refeições \\
\hline Jardim Boa Esperança & 290 refeições \\
\hline Jardim Europa & 290 refeições \\
\hline Jardim São Francisco & 410 refeições \\
\hline Jardim Vila Paulista & 420 refeições \\
\hline TOTAL & 1920 refeições \\
\hline
\end{tabular}

Fonte: Dados da pesquisa, 2015.

Aplicando-se na fórmula do cálculo amostral, considerando-se um nível de confiança de $95 \%$ e um erro de amostral de 5\%, são necessários 321 questionários respondidos, sendo que, destes, serão aplicados 86 questionários na unidade do Jardim Coopagro, 48 na unidade do Jardim Boa Esperança, 48 na unidade do Jardim Europa, 69 na unidade do Jardim São Francisco e 70 na unidade do Jardim Vila Paulista, de acordo com rateio por quantidade de média diária refeições servidas em cada unidade.

\title{
3.2 Modelagem de equações estruturais (MEE)
}

Para análises no campo social, a Modelagem de Equações Estruturais (MEE) se revela eficaz e vantajosa pois, segundo, $\mathrm{CHIN}, 1998$, p.1:

\begin{abstract}
quando aplicados corretamente, os procedimentos baseados em SEM têm vantagens substanciais sobre as técnicas de primeira geração, como análise de componentes principais, análise fatorial, análise discriminante ou regressão múltipla, devido à maior flexibilidade que um pesquisador tem para a interação entre teoria e dados 3 .
\end{abstract}

Essas vantagens se destacam, principalmente, pela flexibilidade que o pesquisador encontra em modelos de relações múltiplas e preditores entre variáveis de critério, para construir variáveis latentes não observáveis, encontrar erros de modelagem em medições para variáveis observadas, e testar estatisticamente

\footnotetext{
3 Tradução livre pelos autores.
} 
pressupostos substantivos/teóricos de medição em relação aos dados empíricos, ou seja, para confirmação (CHIN,1998).

Para representação da modelagem estrutural, são usados os símbolos demonstrados na Quadro 5:

\section{Quadro 5 - Símbolos da Modelagem de Equações Estruturais}

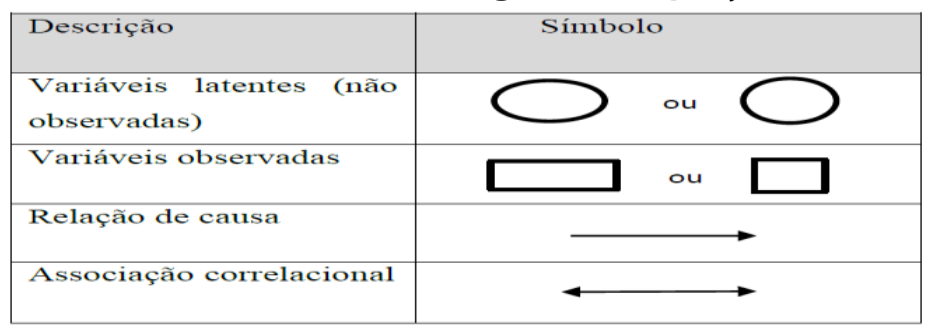

Fonte: PEREIRA, 2013, p. 14 .

As variáveis podem obter dois tipos de relações entre elas: formativa e reflexiva, de modo que a teoria a priori indicará qual o formato dessa relação, assim:

Não há uma resposta definitiva para a questão de quando se deve medir um construto com indicadores reflexivos ou formativos, dado que um construto não é inerentemente reflexivo ou formativo. A especificação, no entanto, dependerá da conceptualização do construto e do objetivo da pesquisa (SILVA, 2014, p. 156).

Em BOLLEN e LENNOX (1991) as duas premissas são especificadas, os refletores são dependentes do valor de uma variável latente, ou seja, a variável latente ajuda na determinação das notas de item, ou observações das variáveis. Por outro lado, a perspectiva formativa se trata dos itens que serão os determinantes da variável latente: variáveis de formação são definidas por seus itens (BAGOZZI e FORNELL,1982; BOLLEN e LENNOX, 1991). hipóteses:

Através do modelo de mensuração proposto neste item, espera-se testar 3

H1: RPS causa efeitos positivos em SU.

H2: RPS causa efeitos positivos em DS.

H3: SU causa efeitos positivos em DS.

Para tanto, será utilizada a metodologia PLS, descrita no próximo item deste trabalho, com ajuda da ferramenta SmartPLS3.

\subsection{Partial least squares (PLS)}

O Partial Least Squares (PLS), ou Mínimos Quadrados Parciais, é uma metodologia de análise estatística de dados que é usada no cruzamento de Modelos de regressão, Modelos de Equações Estruturais (MEE), e vários métodos de Análise de Tabela. Essa metodologia decompõe uma matriz de dados que relaciona uma ou mais variáveis de interesse, como pode-se observar na Figura 1 do item 4.2. Ela é baseada na variância dos construtos para realizar as regressões dos mínimos quadrados parciais e permite representar múltiplas relações simultaneamente especificando a direção causal, adotando o modelo de variáveis latentes ou construtos (não observadas) que são inferidas pelas variáveis observadas para fazer 
análise multivariada da Modelagem de Equações Estruturais (MEE) ou Structural Squation Modeling (SEM), entre outros modelos que se queira observar (CHIN, 1998).

Devido aos inúmeros cálculos com algoritmos complexos e precisos, foi necessária a utilização do software SmartPls, que, ao final da estimação, fornece resultados que ajudam a testar as premissas do modelo de regressão, como o $R$ Square, análise fatorial, a correlação entre as variáveis observáveis, entre outros, que trazem maior facilidade para encontrar os erros de estimativa, variáveis nãosignificativas para o modelo, e possível necessidade de métodos de correção.

A formação da análise da MEE neste trabalho, foi gerada no programa SmartPls versão PLS 3. As variáveis observáveis utilizadas no modelo são formadas pelos itens de questionário, no modelo de escala de Likert de 7 pontos, e foram utilizadas para inferir as variáveis latentes: Gestão dos Restaurantes Populares (GRP), Saúde dos Usuários (SU) e Desenvolvimento Social dos Usuários (DS).

Assume-se que a RPS é uma variável reflexiva, pois os itens relacionados a ela são influenciados pela Gestão dos Restaurantes Populares, ou seja, o Preço da refeição (PR), a Qualidade do alimento (QA), a Higiene Local (HL), a Localização dos RPS (LO), os Equipamentos públicos (EQ) e o Atendimento nos RPs (AT), dependem da gestão dos restaurantes.

Da mesma forma, assumem-se como variáveis reflexivas, a Saúde dos Usuários para com suas variáveis observadas: Aprendizagem segurança alimentar (ASA), Mudança de hábito alimentar (MA), Prática de caminhadas (PC) e Tempo ganho para descanso (TD), e o Desenvolvimento Social, para com suas variáveis observadas: Consumo invertido em bem-estar (CBE), Consumo invertido na região (CR), Tempo gasto (TG), Interação social/humana (ISH), Ganhos de cultura e socialização (GCS).

Seguindo ainda a estruturação, assume-se para a relação multivariada entre as variáveis latentes (construtos), duas análises:

1) A Saúde dos Usuários (SU) é formada pelos Restaurantes Populares (RP),

2) O Desenvolvimento Social dos Usuários (DS) é formado pelos Restaurantes Populares (RP) e pela Saúde dos Usuários (SU).

Com a análise estrutural especificada aqui, obteve-se quanto um construto é responsável pela formação do outro, sabendo-se que não são somente estes formadores ditados no presente trabalho que influenciam no desenvolvimento social e na saúde dos usuários, o que influencia o ajuste do modelo.

\section{Resultados e discussões}

Este tópico tem por objetivo apresentar os resultados dos questionários aplicados nesta pesquisa, bem como das relações das variáveis analisadas na modelagem de equação estrutural.

Na primeira parte, será descrito o perfil dos usuários dos Restaurantes Populares, tanto sociais como econômicos, além da medição da frequência do uso desse programa e a importância do mesmo no cotidiano de quem o utiliza.

$\mathrm{Na}$ segunda parte, através da metodologia Partial Least Square, serão representados os resultados das interações entre as variáveis, Saúde alimentar e desenvolvimento social dos usuários com os serviços prestados nos Restaurantes 
Populares de Toledo/PR, ou seja, os efeitos de causalidade dessa modelagem de equações estruturais.

\subsection{Questionários socioeconômicos}

Embasado nas respostas de 321 questionários válidos, dos 420 questionários aplicados aos usuários dos Restaurantes Populares de Toledo, dentro do período de $23 / 11 / 2015$ a 27/11/2015, assumem-se os resultados, a seguir, com $95 \%$ de confiança e $5 \%$ de erro amostral.

No Quadro 6, destaca-se o montante de homens que frequentam os restaurantes, pois estes são quase que o dobro de mulheres da amostra, mais especificamente, para cada mulher tem-se 1,675 homens frequentando diariamente os Restaurantes Populares em Toledo.

Quadro 6 - Gênero, Idade, Escolaridade dos usuários da amostra
\begin{tabular}{|l|l|l|l|l|l|l|l|l|}
\hline 1. Sexo & FRQ & $\%$ & 2. Idade & FRQ & $\%$ & 3. Escolaridade & FRQ & $\%$ \\
\hline F & 120 & 37,4 & 12 a 19 & 31 & 9,6 & Sem Instrução & 5 & 1,6 \\
\hline M & 201 & 62,6 & 20 a 29 & 83 & 25,9 & Fund. Incompleto & 58 & 18,1 \\
\hline & & & 30 a 49 & 123 & 38,3 & Fund. Completo & 37 & 11,5 \\
\hline & & & Acima de 50 & 84 & 26,2 & Médio Incompleto & 44 & 13,7 \\
\hline & & & & & & Médio Completo & 81 & 25,2 \\
\hline & & & & & & $\begin{array}{l}\text { Superior } \\
\text { Incompleto }\end{array}$ & 37 & 11,5 \\
\hline & & & & & & Superior Completo & 28 & 8,7 \\
\hline & & & & & & Pós-graduado & 31 & 9,7 \\
\hline
\end{tabular}

Fonte: Dados da Pesquisa, 2015.

Com relação a idade, o grupo mais expressivo revelou ter entre 30 e 49 anos, sendo $38,3 \%$ do total, porém, se somar todos os usuários com mais de 30 anos, eles representam a maioria, $64,5 \%$ da amostra, sendo que $40,58 \%$ deste último grupo são pessoas com mais de meio século de vida. Ainda nesta pergunta, identificou-se que 9,6\% da amostra são jovens de até 19 anos, enquanto que quase $26 \%$ têm entre 20 e 29 anos.

Quanto à escolaridade, por ordem de expressividade, em primeiro lugar, com $25,2 \%$ do total da amostra, está o grupo de usuários que possuem Ensino Médio Completo. Em segundo e terceiro lugar encontram-se, respectivamente, Ensino Fundamental Incompleto (18,1\%) e Ensino Médio Incompleto (13,7\%). Somando todos os que ainda não completaram o Ensino Médio, 44,9\% do total da amostra, verifica-se que estes formam a minoria dos usuários, enquanto que ao juntar quem tem pelo menos o Ensino Médio Completo aos que continuaram se instruindo até a Pósgraduação, forma-se o montante de $55,1 \%$ dos usuários.

Mas se separar o Ensino Médio Completo deste último grupo, o total de usuários que possuem Ensino Superior Incompleto até Pós-graduação formam 29,9\% do total. É interessante enfatizar, que, na amostra, identificaram-se mais pessoas pósgraduadas $(9,66 \%)$ do que apenas com Ensino Superior Completo $(8,72 \%)$. Dos 31 pósgraduados, 7 têm renda familiar entre 1 e 2 salários mínimos, 20 têm entre 2 e 6 salários, 3 têm entre 6 e 9, e 1 estava desempregado com nenhuma renda familiar. Assim, ainda considerando que $77,4 \%$ desses almoçam regularmente no Restaurante 
Popular 2 vezes ou mais por semana, e 51,6\% costumam levar seus familiares, sugerese que o preço, neste caso, não é o fator mais atrativo, pois a renda desse grupo é de modo geral maior que nos outros grupos.

Com relação ao Quadro 7, o grupo mais concentrado de renda familiar dos usuários está na faixa salarial de 1 a 2 salários mínimos mensais (45,5\%), seguido pela faixa de 2 a 6 salários mínimos mensais (34\%), e depois de 1 salário mínimo (12,8\%). Apenas 4,6\% têm de 6 a 9 salários mínimos, e um grupo ínfimo de 0,6\% são detentores de 9 salários mínimos ou mais de renda familiar. Somente $2,5 \%$ dos usuários declararam não ter nenhuma renda.

\section{Quadro 7 - Renda Familiar, localização relativa de moradia e estudo}

\begin{tabular}{|c|c|c|c|c|c|c|c|c|}
\hline 4. Renda familiar & FRQ & $\%$ & $\mathbf{5 .}$ Onde mora & FRQ & $\%$ & $\mathbf{6 . ~ O n d e ~ E s t u d a ~}$ & FRQ & $\%$ \\
\hline Nenhuma renda & 8 & 2,5 & Mesmo bairro & 157 & 48,9 & Mesmo bairro & 21 & 6,5 \\
\hline 1 salário mín & 41 & 12,8 & Bairros vizinhos & 87 & 27,1 & Bairros vizinhos & 26 & 8,1 \\
\hline 1 a 2 salários mín & 146 & 45,5 & Outros bairros & 65 & 20,2 & Outros bairros & 26 & 8,1 \\
\hline 2 a 6 salários mín & 109 & 34 & $\begin{array}{c}\text { Não moro em } \\
\text { Toledo }\end{array}$ & 12 & 3,8 & $\begin{array}{c}\text { Não estudo em } \\
\text { Toledo }\end{array}$ & 13 & 4,1 \\
\hline 6 a 9 salários mín & 15 & 4,6 & & & & Não estudo & 235 & 73,2 \\
\hline $\begin{array}{c}\text { mais de 9 salários } \\
\text { mín }\end{array}$ & 2 & 0,6 & & & & & & \\
\hline
\end{tabular}

Fonte: Dados da Pesquisa, 2015.

A localização dos Restaurantes Populares influencia bastante na vida das pessoas que moram no mesmo bairro, pois estes são $48,9 \%$ dos seus usuários, seguidos dos que moram nos bairros vizinhos completando $27,1 \%$, que também são agraciados pela distância relativamente curta.

É interessante frisar que $20,2 \%$ moram em outros bairros e frequentam os Restaurantes Populares, e que somente 25 pessoas das 65 que moram em outros bairros, trabalham no mesmo bairro ou nos bairros vizinhos. Isto implica em 40 pessoas, $12,46 \%$ do total da amostra, que têm preferência pelo Restaurante Popular, apesar da distância não as favorecer. Ademais, 12 pessoas moram em outras cidades, e ao visitar Toledo, decidiram almoçar nesses restaurantes, e um detalhe importante, é que apenas 3 dessas pessoas declararam que é a primeira vez que ali almoçam.

A respeito, da distância entre o local de estudo dos usuários com relação aos restaurantes, não foi verificado tanta importância, considerando que $73,2 \%$ declararam que não estão estudando no momento.

Em análise do Quadro 8, observa-se que a grande maioria trabalha (75,7\%), enquanto $13,7 \%$ se dizem desempregados e 10,6\% aposentados. Dos desempregados, que somaram 44 pessoas, 17 declararam ter entre 12 e 20 anos de idade, 10 entre $21 \mathrm{e}$ 30 anos, 12 entre 31 e 49, e 5 mais de 50 anos. Ou seja, muitos desses não estão em idade propícia para trabalhar ainda. Porém outro dado interessante é que 13 pessoas desempregadas têm pelo menos ensino superior incompleto (6), completo (4) e pósgraduação (3), a renda familiar desses usuários se concentra muito na faixa de 0 a 3 salários mínimos (11 pessoas), enquanto uma pessoa declarou ter renda familiar entre 3 e 6 salários e outra pessoa entre 6 e 9 salários mínimos. Isso implica que, até mesmo as pessoas que têm uma maior escolaridade que frequentam os restaurantes populares em Toledo, sofrem com o desemprego e com uma renda mais restrita nos seus lares. 
No entanto, dos 34 aposentados, 2 revelaram que apesar de aposentados, ainda mantém alguma atividade, um na agricultura, e o outro no setor de comércio, sendo que este último não trabalha em local fixo. Além do mais, dos 45 que responderam que não trabalham, 2 revelaram nas questões posteriores que trabalham em atividades dos setores comércio e construção, porém sem lugar fixo, e, provavelmente, de forma autônoma.

Ao todo, 76,9\% do total da amostra, realizam, então, alguma atividade de trabalho, sendo que $62,7 \%$ destes, trabalham próximo ao Restaurante Popular (Mesmo bairro ou Bairros Vizinhos) em que respondeu ao questionário.

O setor empregatício que mais ocupa os usuários dos Restaurantes Populares é o setor de serviços, com $29,3 \%$ do total da amostra, que representa todos os usuários que trabalham autonomamente, com atividades de manutenção e outros serviços que não estão relacionados ao setor público e nem a atividades em mercados ou feiras e a vendas ou corretagens de bens móveis ou imóveis, que foram designados ao setor de comércio.

Quadro 8 - Emprego, localização relativa do trabalho e setor empregatício

\begin{tabular}{|c|c|c|c|c|c|c|c|c|}
\hline 7. Trabalha & FRQ & $\%$ & 8. Onde trabalha & FRQ & $\%$ & 9. Setor/Ramo & FRQ & $\%$ \\
\hline Sim & 243 & 75,7 & Mesmo bairro & 73 & 22,7 & Agricultura & 3 & 0,9 \\
\hline Não & 44 & 13,7 & Bairros Vizinhos & 82 & 25,5 & Construção & 28 & 8,7 \\
\hline \multirow[t]{9}{*}{ Aposentado } & 34 & 10,6 & Outros bairros & 54 & 16,8 & Empresário & 6 & 1,9 \\
\hline & & & $\begin{array}{c}\text { Não trabalho em } \\
\text { Toledo }\end{array}$ & 5 & 1,6 & Comércio & 21 & 6,5 \\
\hline & & & $\begin{array}{c}\text { Não trabalho local } \\
\text { fixo }\end{array}$ & 33 & 10,3 & Indústria & 16 & 5 \\
\hline & & & Não trabalho & 74 & 23,1 & Serviços & 94 & 29,3 \\
\hline & & & & & & Setor público & 35 & 10,9 \\
\hline & & & & & & Setor financeiro & 2 & 0,6 \\
\hline & & & & & & Transporte & 16 & 5 \\
\hline & & & & & & Em branco & 26 & 8,1 \\
\hline & & & & & & Não trabalho & 74 & 23,1 \\
\hline
\end{tabular}

Fonte: Dados da pesquisa, 2015.

Dessa forma, no setor público tem-se 10,9\% de ocupação, no setor de construção $8,7 \%$, no setor de comércio $6,5 \%$, no setor industrial $5 \%$, e no setor de transporte, que representa os usuários que se declararam motoristas, $5 \%$ também. Em menores proporções identificaram-se 3 pessoas do setor agrícola, 2 pessoas do setor financeiro, e 6 empresários.

Do total de usuários que não trabalham, 30 são homens e 44 são mulheres, um número bem expressivo para as mulheres, contando que essas representam pouco mais da metade do montante de homens na amostra, e do total que deixaram a questão sobre o setor empregatício em branco, 16 são homens enquanto que 10 são mulheres. 
Quadro 9 - Frequência de uso dos Restaurantes Populares para o usuário e sua família

\begin{tabular}{|c|c|c|c|c|c|}
\hline 10. Frenquência & FRQ & $\%$ & 11. Família & FRQ & $\%$ \\
\hline 1 vez por semana & 21 & 6,5 & Sim & 161 & 50,1 \\
\hline 2 vezes por semana & 41 & 12,8 & Não & 154 & 48 \\
\hline 3 vezes por semana & 49 & 15,3 & $1^{\text {a }}$ vez hoje & 6 & 1,9 \\
\hline 4 vezes por semana & 42 & 13,1 & & & \\
\hline 5 vezes por semana & 145 & 45,2 & & & \\
\hline Poucas vezes & 11 & 3,4 & & & \\
\hline $1^{\text {a }}$ vez que veio & 6 & 1,9 & & & \\
\hline Raramente & 5 & 1,5 & & & \\
\hline Quando Tenho Tempo & 1 & 0,3 & & & \\
\hline
\end{tabular}

Fonte: Dados da pesquisa, 2015.

De acordo com a Quadro 9, a grande maioria dos usuários são assíduos, frequentando os restaurantes todos os dias (45,2\%), dos demais 13,1\% almoçam, em média, quatro vezes por semana, $15,3 \%$ almoçam três vezes por semana, enquanto que $12,8 \%$ almoçam duas vezes por semana e $6,5 \%$ almoçam pelo menos uma vez por semana. De modo geral, são poucos os que não têm uma rotina de frequência e responderam outras opções como: "poucas vezes", "raramente", "quando tenho tempo" e "primeira vez que venho", totalizando apenas 7,1\% do total da amostra.

Na questão "Você costuma vir com a família no Restaurante Popular?", pouco mais da metade respondeu que sim, totalizando 50,1\% dos usuários, enquanto que $48 \%$ não costumam levar a família, e 1,9\% estavam almoçando pela primeira vez no Restaurante Popular de Toledo/PR.

Sobre a influência para almoçarem no Restaurante Popular pela primeira vez, grande parte respondeu que o preço foi o fator decisivo (34,6\%), mas também se destacam os fatores "convite de colega", que representa $27,7 \%$ do total da amostra, o alimento servido com $18,4 \%$, e a proximidade/localidade com $16,5 \%$. Os fatores "falta de tempo" ( $0,9 \%)$, "curiosidade" $(1,6 \%)$ e o fato de "ter nutricionistas" trabalhando no local ( $0,3 \%)$ também foram lembrados como outros motivos influenciadores.

Quadro 10 - Influência para a primeira refeição e outros Restaurantes Populares
\begin{tabular}{|c|c|c|c|c|c|}
\hline $\mathbf{1 2 . 1}^{\text {a }}$ Influência & FRQ & $\%$ & 13. Ida a outros RPs & FRQ & $\%$ \\
\hline Convite de colega & 89 & 27,7 & Só neste & 137 & 43 \\
\hline Preço & 111 & 34,6 & 1 vez em outro & 50 & 15,1 \\
\hline O alimento & 59 & 18,4 & 2 vezes ou mais em outro & 112 & 35 \\
\hline Estava próximo & 53 & 16,5 & Geralmente em outro & 16 & 5 \\
\hline Falta de Tempo & 3 & 0,9 & $1^{\text {a }}$ vez hoje & 6 & 1,9 \\
\hline Curiosidade & 5 & 1,6 & & & \\
\hline Tem Nutricionistas & 1 & 0,3 & & & \\
\hline
\end{tabular}

Fonte: Dados da pesquisa, 2015.

Na última questão desta parte socioeconômica, perguntou-se aos usuários se já frequentaram algum dos outros Restaurantes Populares de Toledo/PR, além do qual eles estavam no momento, $43 \%$ deles responderam que nunca haviam almoçado em outra unidade, 15,1\% haviam almoçado apenas uma vez em outra unidade, 35\% almoçaram duas vezes ou mais em outra unidade e $5 \%$ geralmente almoçam em outra unidade. O interessante desse resultado é que cerca de $45 \%$ dos usuários já tiveram 
contato com outras unidades dos Restaurantes Populares, e que, provavelmente, procuram por esse serviço quando estão em outros bairros em condições que se divergem do seu cotidiano.

\subsection{Mensuração da modelagem de equações estruturais}

Figura 1 - Resultados diretos das relações estruturais e índice $R$ Square

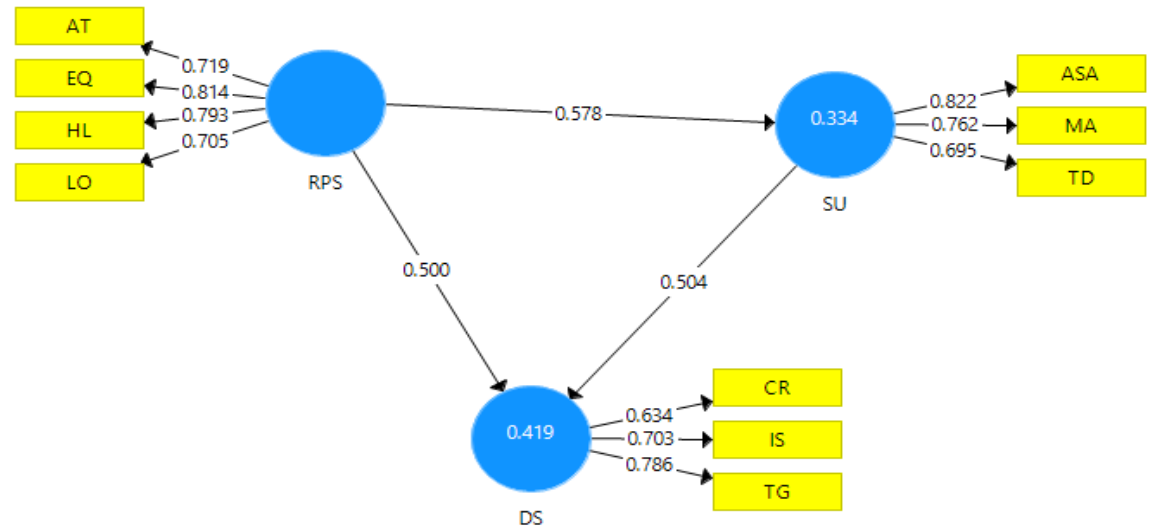

Fonte: Dados da Pesquisa, $2015^{4}$.

A modelagem de equação estrutural analisada (Figura 1), indica os efeitos diretos das relações entre as variáveis latentes, valor ao meio das setas internas, o índice $R$ Square sobre o ajuste do modelo, valor dentro dos círculos, e os loadings, valores ao meio das setas externas. Como este é um modelo reflexivo as setas seguem dos construtos em direção aos indicadores, carregando o valor do construto, se fosse o caso de um modelo formativo, esses valores seriam determinados "pesos" e as variáveis não iriam refletir a variável, mas formá-la.

Conforme se pode observar, algumas das variáveis previstas no Quadro 3, para formação da MEE, não estão mais inclusas no modelo. Foi necessário retirá-las, pois ao analisar suas confiabilidades (Indicators Reliability) não foi possível confirmá-las, dessa forma, não se poderia confiar nos resultados do modelo.

Isto significa que, para as variáveis observadas Preço (PR), Qualidade do alimento (QA), Prática de caminhada (PC), Consumo Invertido em bem-estar (CBE) e Ganhos com Cultura e Socialização (CS), os valores de Indicators Reliability foram menores que 0,4 para a regressão PLS.

\subsubsection{Confiabilidade e validade dos resultados}

No modelo reflexivo, alguns valores devem ser analisados para confirmar a consistência dos efeitos das relações multivariadas calculadas no programa SmartPIs. Para isso, o Quadro 11 contém alguns dados a serem verificados.

\footnotetext{
4 Para o cálculo dos resultados PLS, rodou-se com 5000 para número máximo de iterações. Constam saídas do programa SmartPIs PLS 3, com os resultados da MEE.
} 
Quadro 11. Resultados para modelos reflexivos

\begin{tabular}{|c|c|c|c|c|c|}
\hline Variável Latente & Indicadores & Cargas & Indicators Reliability & Composite Reliability & AVE \\
\hline \multirow{4}{*}{ RPS } & AT & 0,719 & 0,516961 & \multirow[b]{4}{*}{0,844} & \multirow[b]{4}{*}{0,576} \\
\hline & $\mathrm{EQ}$ & 0,814 & 0,662596 & & \\
\hline & $\mathrm{HL}$ & 0,793 & 0,628849 & & \\
\hline & LO & 0,705 & 0,497025 & & \\
\hline \multirow{3}{*}{ SU } & ASA & 0,822 & 0,675684 & \multirow[b]{3}{*}{0,805} & \multirow[b]{3}{*}{0,580} \\
\hline & MA & 0,762 & 0,580644 & & \\
\hline & TD & 0,695 & 0,483025 & & \\
\hline \multirow{3}{*}{ DS } & $C R$ & 0,634 & 0,401956 & \multirow[b]{3}{*}{0,752} & \multirow[b]{3}{*}{0,505} \\
\hline & IS & 0,703 & 0,494209 & & \\
\hline & TG & 0,786 & 0,617796 & & \\
\hline
\end{tabular}

Fonte: Dados da Pesquisa, 2015.

A primeira coisa a se verificar é a confiabilidade de cada indicador, que consta na coluna Indicator Reliability (Confiabilidade do indicador), esses valores são os quadrados das cargas, e, para pesquisas exploratórias, são considerados aceitáveis acima de 0,4 e preferíveis acima de 0,7. De acordo com os valores dos quadrados, os indicadores LO, TD, CR, e IS, apesar de consideradas significantes, seus valores implicam em mais variância de erro do que variância explicada na variância da medida, enquanto que todos os outros indicadores têm mais variância explicada, de acordo com a porcentagem dos seus quadrados. Por exemplo, o ASA tem 67,5\% de variância explicada e 32,5\% de variância de erro (HAIR, et al, 2009; WONG, 2013).

Na coluna Composite Reliability (Confiabilidade composta), se demonstra a confiabilidade composta referente às variáveis latentes, esse valor deve ser de 0,7 ou superior, porém, para uma pesquisa exploratória, 0,6 ou superior é aceitável. Verificase confiabilidade para as variáveis RPS, SU, e DS, assim, todas as medidas consistentemente representam o mesmo construto, há consistência interna (BAGOZZI e YI, 1988).

O Average Variance Extracted (AVE) é a variância média extraída de cada variável latente, e é usada para verificar a validade convergente. A validade convergente mede a relação entre duas medidas de um mesmo construto, para testar se o modelo calculado é adequado à teoria ou conceituação da pesquisa. Se der acima de 0,5, a variável é convergentemente validada (HAIR, et al, 2009; WONG, 2013). No geral, quanto à confiabilidade e validade, esse modelo de mensuração se provou adequado.

Outra análise dos resultados é sobre o ajuste do modelo, medido através do $R$ Square, que é a porcentagem da variação da variável endógena explicada pelas variáveis exógenas. É determinado que valores de o,7 ou mais representam um ótimo ajuste, porém valores menores podem ser considerados, enquanto representam um ajuste moderado (WONG, 2013).

Conclui-se que a variação do Desenvolvimento Social dos Usuários é razoavelmente explicada pela variação dos Serviços Prestados pelos Restaurantes Populares e pela variação da Saúde Alimentar dos Usuários em 41,9\%, enquanto que, a variação da Saúde Alimentar dos Usuários é explicada razoavelmente pela variação dos Serviços Prestados pelos Restaurantes em 33,4\%.

\subsubsection{Análise dos resultados do PLS}


De acordo com WONG (2013), os Path Coefficients, também conhecidos como coeficientes estruturais, são os resultados da regressão multivariada que indicam a força do efeito que uma variável exógena pode causar em uma variável endógena, sendo que valores acima de 0,1 são considerados como efeitos estatisticamente significativos, menos do que isso, insignificantes.

Tabela 1 - Efeitos Resultantes do PLS

\begin{tabular}{cccc}
\hline Efeitos Diretos & DS & RPS & SU \\
\hline DS & & & \\
RPS & 0,209 & & 0,578 \\
SU & 0,504 & & \\
Efeitos Indiretos & DS & RPS & SU \\
DS & 1,000 & & \\
RPS & 0,291 & 1,000 & \\
SU & & & 1,000 \\
Efeitos Totais & DS & RPS & SU \\
DS & 1,000 & & \\
RPS & 0,500 & 1,000 & 0,578 \\
SU & 0,504 & & 1,000 \\
\hline
\end{tabular}

Fonte: Dados da Pesquisa, $2015^{5}$.

A hipótese nula, para qualquer dos coeficientes de efeitos foi descartada, ao nível de 5\% significância, formato bicaudal, conforme se constatou nos resultados calculados dos $T$ Statistics, critério > 1,96, e $P$ value, critério < 0,05, Tabela 2, pelas verificações da opção Bootstrappings do SmartPLS3.

Tabela 2 - T Statistics e P Values dos efeitos diretos.

\begin{tabular}{cccc}
\hline & Path coefficients & T Statistics $(|\mathrm{O} / \mathrm{STDEV}|)$ & P Values \\
\hline RPS $\rightarrow$ DS & 0,209 & 3,517 & 0,000 \\
RPS $\rightarrow$ SU & 0,578 & 12,189 & 0,000 \\
SU $\rightarrow$ DS & 0,504 & 9,044 & 0,000 \\
\hline
\end{tabular}

Fonte: Dados da Pesquisa, $2015^{6}$.

A H1 afirma que os Restaurantes Populares causam um efeito positivo na Saúde Alimentar dos Usuários. Essa hipótese é confirmada, pois o coeficiente direto desta relação é 0,578 , com um $P$ value de 0,000 .

A H2 afirma que os Restaurantes Populares causam um efeito positivo no Desenvolvimento Social dos Usuários. Essa hipótese é confirmada, pois o coeficiente direto desta relação é 0,209 , com um $P$ value de 0,000 .

A H3 afirma que a Saúde Alimentar dos Usuários causa um efeito positivo no Desenvolvimento Social dos Usuários. Essa hipótese é confirmada, pois o coeficiente direto desta relação é 0,504, com um $P$ value de 0,000.

\footnotetext{
${ }^{5}$ Saída do programa SmartPLS3.

${ }^{6}$ Saída do programa SmartPLS3.
} 
Além dos efeitos diretos que tiveram as hipóteses confirmadas, revela-se também o efeito indireto entre os Restaurantes Populares e o Desenvolvimento Social dos Usuários observado na Tabela 3.

Tabela 3 - T Statistics e $P$ Values dos efeitos indiretos

Path coefficients

\begin{tabular}{cccr}
\hline & Path coefficients & T Statistics (|O/STDEV $\mid)$ & P Values \\
\hline $\begin{array}{l}\text { RPS } \\
\rightarrow \text { DS }\end{array}$ & 0,291 & 7,123 & 0,000 \\
\hline
\end{tabular}

Fonte: Dados da Pesquisa, $2015^{7}$.

Confirma-se a existência de um efeito indireto positivo dos Restaurantes Populares no Desenvolvimento Social dos Usuários, contando com um coeficiente estrutural de 0,291 e $P$ value de 0,000.

A soma dos efeitos diretos e indiretos dos RPS sobre o Desenvolvimento Social totalizam 0,500 , demonstrando um efeito positivo bastante forte, tal qual o efeito dos RPS sobre a Saúde Alimentar. Isso significa que os serviços prestados nos Restaurantes Populares aos usuários, são muito importantes na transformação, para melhor, da saúde alimentar e também para geração de desenvolvimento social na sua forma de bem-estar e inclusão social, conforme foi analisado aqui esse desenvolvimento.

\section{Conclusão}

Através de questionários destinados aos usuários dos Restaurantes Populares, identificaram-se algumas características das pessoas que os utilizam e também foram levantados os dados necessários para observar, através da metodologia PLS de Modelagem de Equações Estruturais, a influência/relação entre os serviços prestados pelo programa, e a saúde e desenvolvimento social dos seus usuários.

Concluiu-se quanto ao perfil dos usuários, que $62,6 \%$ são do sexo masculino, que a maioria tem mais de 30 anos de idade $(64,5 \%)$ e apenas pouco mais da metade possui, pelo menos, o Ensino Médio Completo (55,1\%). A idade predominante explica os $75,7 \%$ que estão trabalhando e os $10,6 \%$ que são aposentados, além dos $73,2 \%$ dos usuários que não estão estudando no momento, apontando a realidade de vida estudantil desses usuários que poderia ser estendida como a realidade do próprio bairro ou região, mas cabe a outro estudo esta análise.

Uma grande parcela dos usuários informou que conta com até dois salários mínimos de renda familiar mensal (45,5\%), o que se relaciona ao fato de $34,6 \%$ dos usuários apontarem o preço do alimento como o fator que os influenciou a irem aos restaurantes populares na primeira vez. Observando por esse ângulo, os restaurantes Populares, ao fornecerem o alimento a um preço mais acessível aos usuários, melhoram as condições financeiras, incrementando a renda real disponível, caso contrário não seria considerado um fator tão importante pelos próprios usuários.

Os setores que mais empregam os usuários são, respectivamente, o Setor de Prestação de Serviços (29,3\%), o Setor Público (10,9\%) e o Setor de Construção $(8,7 \%)$, e $42,2 \%$ dos usuários trabalham próximos aos Restaurantes Populares, no mesmo bairro ou num bairro vizinho.

\footnotetext{
7 Saída do programa SmartPLS3.
} 
Além disso, a maioria dos usuários mora nas proximidades dos Restaurantes Populares, $48,9 \%$ no mesmo bairro e $27,1 \%$ nos bairros vizinhos, concomitantemente, $45,2 \%$ dos usuários almoçam as cinco vezes por semana nos restaurantes populares, 92,8\% almoçam pelo menos uma vez por semana e 50,1\% levam sua família para almoçar junto.

A partir desses dados, conclui-se que a localização dos Restaurantes Populares é importante no cotidiano das pessoas que os utilizam no município de Toledo, pois se demonstra nesses resultados um vínculo diário/semanal entre os usuários e os restaurantes, tanto que 55,1\% dos usuários já almoçaram em outras unidades dos Restaurantes Populares, nos momentos em que estavam em outros bairros, cumprindo assim a sua prática de utilização deste serviço.

Quanto aos resultados do PLS, todas as três hipóteses do modelo foram confirmadas, relembrando: H1: PS causa efeitos positivos em SU; H2: RPS causa efeitos positivos em DS; H3: SU causa efeitos positivos em DS.

Deve-se destacar que, apesar desses resultados representarem muito bem as esperanças iniciais da pesquisa, poderiam ter sido melhores, não fossem as exclusões forçadas de variáveis que eram consideradas importantes para a análise, o caso do Preço, Qualidade do alimento, Prática de caminhada, Consumo Invertido em bemestar e Ganhos com Cultura e Socialização.

Porém essas variáveis foram consideradas insignificantes para o modelo, por terem suas variâncias distintas da maioria das variáveis. Mas isso não quer dizer que são variáveis insignificantes para os usuários, na verdade, evidenciou que não são somente as variáveis que se aparentavam óbvias, preço e qualidade do alimento, que influenciam a frequência dos usuários, bem como seu bem-estar e saúde, mas outras variáveis são importantes como a higiene do local, os equipamentos fornecidos, a localização e o atendimento que eles recebem, variáveis essas, que representam a preocupação com os usuários, da mesma forma que qualquer estabelecimento se preocupa com o bem-estar do seu cliente. Ou seja, os usuários se sentem à vontade no Restaurante Popular, da forma como deve ser, o povo se apropriando dos bens públicos.

A apropriação desse programa pelos usuários e os benefícios recebidos em troca, sugerem para este município, impactos, também, na área da saúde, pois, na medida em que os usuários dos restaurantes populares se tornam mais saudáveis, acabam por precisar menos do serviço de saúde pública.

Assim, os Restaurantes Populares na cidade de Toledo-PR estão cumprindo com seus objetivos enquanto instrumento de políticas sociais, melhorando a saúde alimentar, elevando a renda real, e o desenvolvimento social dos usuários. Conforme esses resultados, se afirma, com relativa tranquilidade, que a administração pública tem operacionalizado esse programa de forma eficiente, e merecedora dos prêmios e títulos que tem recebido.

Em 2015, foram aprovados mais três Restaurantes Populares, para os bairros Gisela, Panorama II, que deverão entrar em funcionamento ainda em 2016, e Jardim La Salle, dentro da Universidade Estadual do Oeste do Paraná, que já está em funcionamento desde abril de 2016, atendendo a população da região e os universitários. Espera-se que a população desses bairros seja beneficiada com ganhos em saúde e desenvolvimento social, e que seja analisado periodicamente o comportamento das relações estudadas com essa pesquisa. 


\section{REFERÊNCIAS}

ALEXANDRE, J.W. C. et. al. Análise do número de categorias da escala de Likert aplicada à gestão pela qualidade total através da teoria da resposta ao item. XXIII Encontro Nac. de Eng. de Produção. Ouro Preto, 21 a 24 de out de 2003. Disponível em: <http://www.abepro.org.br/biblioteca/enegep2003_tro201_0741.pdf >. Acesso em 13 de novembro de 2015.

BAGOZZI, R. P., \& Fornell, C. Theoretical concepts, measurements, and meaning. In C. Fornell (Ed.), A second generation of multivariate analysis, Volume 2. New York: Praeger Publishers, 1982. p. 24-38.

BAGOZZI, R. P.; YI, Y. On the evaluation of structural equation models. Journal of the academy of marketing science, v. 16, n. 1, 1988. p. 74-94.

BOLLEN, K., \& Lennox, R. Conventional wisdom on measurement: A structuralequation perspective. Psychological Bulletin, v. 110, n. 2, p. 305-314, 1991.

BRASIL. Para cada R\$ 1 no Bolsa Família, PIB cresce R\$ 1,78. 2013. Disponível em: <http://www.brasil.gov.br/economia-e-emprego/2013/10/para-cada-r-1-no-bolsafamilia-pib-cresce-r-1-78>. Acesso em 13 de novembro de 2015.

BRASIL. Portal da transparência: MDS Toledo. 2015. Disponível em:

<http://www.portaltransparencia.gov.br/convenios/convenioslista.asp?uf=pr\&codm unicipio $=7927 \&$ codorgao $=55000 \&$ tipoconsulta $=1 \&$ periodo $=\& P a g i n a=1>$. Acesso em 13 de novembro de 2015 .

CHIN, W. W. Issues and opinion on structural equation modeling. MIS Quarterly, 1998.

CONSEA - Conselho Nacional de Segurança Alimentar e Nutricional. Construção do Sistema e da Política Nacional de Segurança Alimentar e Nutricional: a experiência brasileira. Brasília. 2009.

FAO - Unidade de Coordenação de Projetos da FAO para a Região Sul Brasil. Plataforma de Boas Práticas Para o Desenvolvimento Sustentável 2016. Disponível em: <http://www.boaspraticas.org.br/index.php/pt/areas-

tematicas/alimentacao/481-cozinha-social-e-restaurantes-populares $>$. Acesso em 13 de maio de 2016.

FERRAZ, L. et al. Avaliação dos serviços de saúde na ótica dos usuários. Revista

Políticas Públicas, v. 17, n. 2, p. 414-423, São Luiz, 2013. 
FUNDAÇÃO BANCO DO BRASIL. Dois projetos do Paraná são premiados na $7^{\text {a }}$ edição do Prêmio Fundação Banco do Brasil de Tecnologia Social. 2013. Disponível em: <https://www.fbb.org.br/reporter-social/noticias/dois-projetos-do-parana-saopremiados-na-7-edicao-do-premio-fundacao-banco-do-brasil-de-tecnologiasocial.htm>. Acesso em 04 de julho de 2015.

HAIR, J. F. et al. Análise multivariada de dados. Bookman Editora, 2009.

HENRIQUE, J. S. A Agricultura Familiar e o Programa de Aquisição de Alimentos (PAA): Um Estudo na Cidade de Toledo-Pr. In: X ECOPAR, Toledo, 2013.

IBGE - INSTITUTO BRASILEIRO DE GEOGRAFIA E ESTATÍSTICA. Diretoria de Pesquisas, Coordenação de Trabalho e Rendimento, Pesquisa Nacional por Amostra de Domicílios. 2013. Disponível em: <http://www.ibge.gov.br/home/estatistica/populacao/ seguranca_alimentar_2013/default_xls_2013.shtm>. Acesso em: 18 de Junho de 2015.

IPEADATA - INSTITUTO DE PESQUISA EM ECONOMIA APLICADA: Banco de Dados do Instituto de Pesquisa em Economia Aplicada. Social. 2015. Disponível em: < http://www.ipeadata.gov.br/ >. Acesso em: 07 de Setembro de 2015.

MDA. PAA. 2015. Disponível em: <http://www.mda.gov.br/sitemda/secretaria/safpaa/sobre-o-programa>. Acesso em: 13 de novembro de 2015.

MDS. Manual Programa Restaurante Popular. 2004. Disponível em: $<$ http://bvsms.saude.gov.br/bvs/publicacoes/projeto_logico_restaurante_popular.p df $>$. Acesso em 16 de agosto de 2015.

MDS. Restaurante popular: apresentação do programa. 2007a. Disponível em: < http://www.ufjf.br/renato_nunes/files/2011/04/Apresentacao-do-ProgramaRestaurantes-Populares.pdf $>$. Acesso em 13 de novembro de 2015.

MDS. Restaurantes populares: roteiro de implantação 2007. 2007b. Disponível em: < http://docslide.com.br/documents/roteiro-de-implantacao-restaurantes-popularesvisualizacao.html>. Acesso em 13 de novembro de 2015.

PEREIRA, Suziane dos Santos. Modelagem de Equações Estruturais no Software R. Instituto de Matemática Departamento de Estatística - UFRGS. Porto Alegre, 2013.

PLANSAN - Plano Nacional de Segurança Alimentar e Nutricional. Balanço das Ações do Plano Nacional de Segurança Alimentar e Nutricional 2012 - 2015. Brasília. 2014.

PREFEITURA DE TOLEDO. Restaurantes populares. 2014. Disponível em: <http://www.toledo.pr.gov.br/portal/restaurantes-populares/restaurantespopulares>. Acesso em 13 de novembro de 2015. 
SANTOS, G. E. de O. Cálculo amostral: calculadora on-line, 2015. Disponível em: <http://www.calculoamostral.vai.la>. Acesso em: 17 de Novembro de 2015.

SILVA, A. S. da. Um modelo de antecedentes para a cocriação de valores em serviços de geriatria na cidade de São Paulo: Uma aplicação da modelagem de equações estruturais. Dissertação. USCS - Universidade Municipal de São Caetano do Sul. São Caetano do Sul, 2014.

SILVA, J. G. et al. Fome zero: a experiência brasileira. MDA, 2010. Disponível em: <http://www.mda.gov.br/sitemda/sites/sitemda/files/user_arquivos_64/pageflip4204234-487363-It_Fome_Zero_A_experinc-1750637.pdf $>$. Acesso em $13 \mathrm{de}$ novembro de 2015 .

VASCONCELOS, F. A. G. Combate à fome no Brasil: uma análise histórica de Vargas a Lula. Revista de Nutrição. v. 18, n. 4, Campinas, 2005. p. 439-457.

WONG, K. K. K. Partial least squares structural equation modeling (PLS-SEM) techniques using SmartPLS. Marketing Bulletin, v. 24, n. 1, p. 1-32, 2013.

ZANINI, Elaine de Oliveira. Prospectiva estratégica para análise da interação entre as políticas públicas relacionadas aos restaurantes populares: um estudo de caso no munícipio de Toledo - PR. Toledo, 2015. Dissertação. Mestrado em Desenvolvimento Regional e Agronegócio - Programa de Pós-Graduação Stricto Sensu em Desenvolvimento Regional e Agronegócio, UNIOESTE, 2015.

Mirian Beatriz Schneider. Professora Associada do Programa de Pós-Graduação em Desenvolvimento Regional e Agronegócio, do Programa de Pós-Graduação em Economia e do Colegiado do Curso de Ciências Econômicas da Universidade Estadual do Oeste do Paraná (Unioeste) - Campus de Toledo. mirianbraun@hotmail.com 